\title{
Effects of different growing media on the cut flower performances of oriental two Lilium varieties
}

\author{
Özgül Karagüzel \\ (Bati Akdeniz Agricultural Research Institute, Vegetables and Ornamental Plants Department, Ministry of Agriculture and Forestry, \\ Antalya 07100, Turkey)
}

\begin{abstract}
In this study, six different growing media (peat+pumice: 1:1, v/v; peat+perlite: 1:1, v/v; rice hull+pumice: 1:2, v/v; coarse sand+peat: $2: 1, \mathrm{v} / \mathrm{v}$; soil; and cocopeat) were evaluated for their effects on the plant growth and flower quality of the oriental 'Siberia' and 'Vespucci' lily varieties. Seven hundred and twenty bulbs were planted in perforated plastic crates and placed in an unheated greenhouse. The physical and chemical properties of the growing media were examined. The number of days to flowering, plant height, the number of flowers, fresh stem weight, the number of leaves and vase life were investigated in the study. The results indicated that the use of soilless growing media significantly affected plant growth and flower quality when compared with soil. The obtained values varied by substrate type. The earliest flowering time (154.78 d) and the longest plant height $(120.82 \mathrm{~cm}$ in the 'Siberia' variety) were determined in peat+pumice, whereas the largest number of flowers (7 flowers in Siberia; 5.67 flowers in Vespucci) and the highest stem weight (266.13 $\mathrm{g}$ in Vespucci; $353.91 \mathrm{~g}$ in Siberia) were recorded in cocopeat. The vase life of the plants grown in soil was longer than that of the plants grown in the soilless culture. Regarding the number of leaves, rice hull+pumice ( 57.42 leaves) and sand+peat (54.46 leaves) gave the best results.
\end{abstract}

Keywords: Lilium varieties, growing media, plant growth, flower quality

DOI: $10.25165 /$ j.ijabe.20201305.5173

Citation: Karagüzel Ö. Effects of different growing media on the cut flower performances of oriental two Lilium varieties. Int J Agric \& Biol Eng, 2020; 13(5): 85-92.

\section{Introduction}

Genus 'Lilium' belongs to the Family 'Liliaceae', which comprises over 180 species $^{[1]}$. Lilium consists of thousands of cultivars that are classified in different hybrid groups and it is one of the most popular ornamental bulbous flowers throughout the world $^{[2]}$. Asiatic and Oriental hybrid Lilium varieties in particular are popular in the international market. The production of Lilium has also been increasing rapidly due to the increasing demand in recent years. Approximately 6400 hectares of agricultural land was allocated for the production of lily bulbs in $2017^{[3]}$. With 297.2 million units, Lilium ranked 6th among the most sold cut flower species in the auction in the Netherlands ${ }^{[4]}$. Lilies are usually produced in the field or the greenhouse with a soil or soilless culture medium. Soil-borne diseases and pests are two of the most important problems encountered in the cultivation of cut flower Lilium. These problems substantially reduce flower quality. Therefore, soilless culture has become the preferred technique in ornamental plants among the new growing methods. The properties of the growing media used in the soilless culture either directly or indirectly affect yield and quality.

The quality of the plants grown in the soilless culture is markedly better than that of the plants grown in conventional soil. However, it is quite essential to determine the appropriate growing media and the organic or inorganic substrates used. There are many local soilless culture substrates used in different countries

Received date: 2019-05-29 Accepted date: 2019-07-19

Biographies: Özgül Karagüzel, PhD, Researcher, research interest: ornamental plants. Vegetables and Ornamental Plants Department, Bati Akdeniz Agricultural Research Institute, Ministry of Agriculture and Forestry Antalya 07100, Turkey. Tel: +90-533-7432144, Email: tezkara@yahoo.com. and the use of local and cheap soilless growing media with convenient physical and chemical properties is suggested all over the world. The properties of a good hydroponic growing medium should be having highly porous and stable organic matter, good water holding capacity and low salt concentration $(\mathrm{Na}, \mathrm{Ca}$, and $\mathrm{Cl}$ ions), adequate humidity and ventilation, and optimum $\mathrm{pH}$ (5.0-6.5 and electrical conductivity (EC) $(0.6 \mathrm{mS} / \mathrm{cm})$ (for potted plants) ${ }^{[5]}$. Soilless culture in bags, pots, plastic crates or trays is the simplest, easiest, and economical way of growing plants. The suitability of different substrates for ornamental plants and their effect on growth, yield and product quality have been investigated by some researchers around the world. Fascella and Zizzo ${ }^{[6]}$ reported that the soilless cultivation of roses in perlite or cocopeat increased yield and stem quality and that it might be related to the higher water holding capacity and cation exchange capacity of cocopeat.

Due to the improved aeration and water retention ability, the soilless culture of gerbera produced in the perlite+zeolite $(1: 1)$ substrate yielded higher than the other mixtures. On the other hand, especially in the Netherlands and Canada, cocopeat has been highly demanded by ornamental sectors ${ }^{[7]}$. Ryota et al. ${ }^{[8]}$ reported that high-quality cut flowers of oriental hybrid lily were obtained from the solid medium culture, which was better than the hydroponic culture system. However, there are not many studies about different solid medium cultures in lily production. The objective of this study is to evaluate the effects of different media on plant growth and flower quality in order to improve the production of cut flower lilies.

\section{Materials and methods}

This research was conducted in an unheated polyethylene-covered greenhouse of $160 \mathrm{~m}^{2}$ located in Bati Akdeniz Agricultural Research Institute $\left(36.56^{\circ} \mathrm{N}, 30.53^{\circ} \mathrm{E}\right.$, and 
altitude 28) between 2011-2013 (in Antalya, Turkey). During the research, the temperature and humidity values for the 1 st and 2 nd years were recorded by means of a HOBO device (Figure 1).
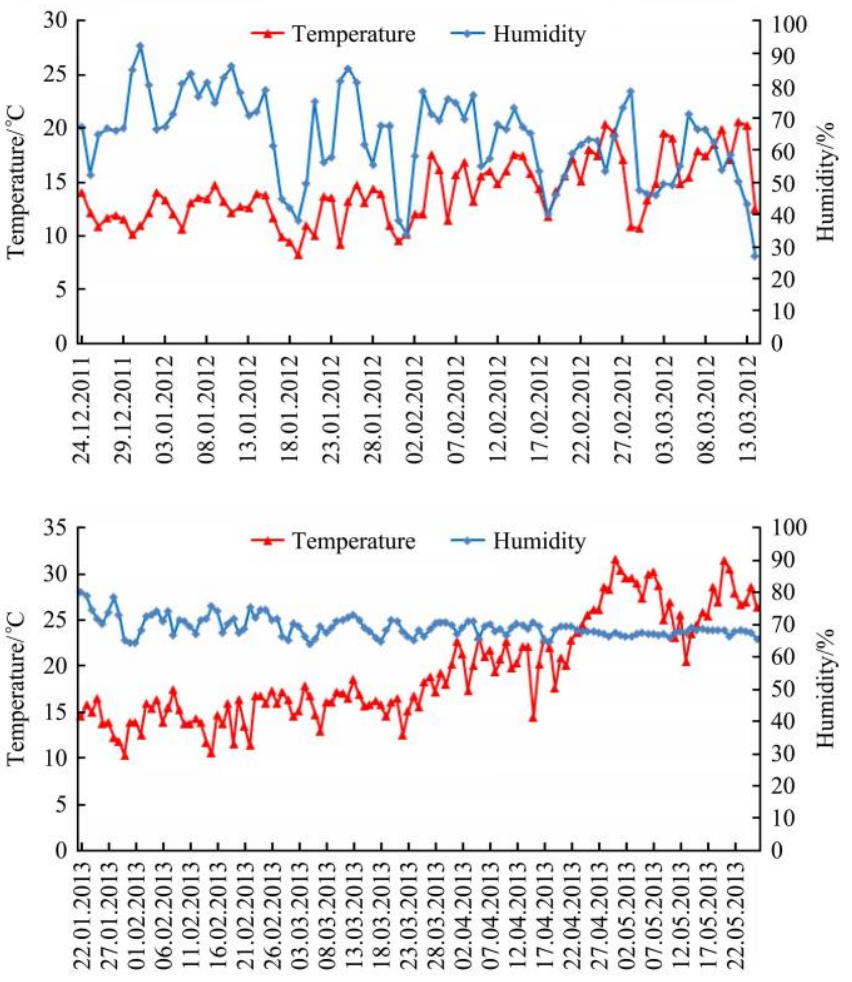

Figure 1 Mean temperature and relative humidity measured in the greenhouse (the 1st and 2nd years)

The optimum temperature conditions for ideal Lilium cultivation are $12^{\circ} \mathrm{C}-25^{\circ} \mathrm{C}$, and the optimum humidity conditions are $65 \%-85 \%$. In this study, the lowest and highest temperature values observed in the first year were $8.2^{\circ} \mathrm{C}$ and $20.3^{\circ} \mathrm{C}$, and the lowest and highest humidity values were $27.2 \%$ and $92.2 \%$. In the second year, the lowest and highest temperature values were $10^{\circ} \mathrm{C}$ and $31^{\circ} \mathrm{C}$, humidity values were $64 \%-80 \%$. According to these results, although the humidity values in the first year were slightly out of average, the average temperature and humidity values measured in both years provided the desired conditions for lily growing.

\subsection{Plant material}

Two cultivars of commercial oriental lilies (Lilium L.) 'Vespucci' and 'Siberia' - (the average bulb circumference was $16 / 18 \mathrm{~cm}$ for both varieties) were used as the plant materials. The Oriental hybrid group has pink or white flowers, strong odor, sturdy stems, broad dark green leaves, and different flowering properties from early (L. rubellum) to late flowering (L. nobilissimum $)^{[9]}$. The 'Vespucci' variety is a white-colored variety; its flowering time is $90 \mathrm{~d}$; its plant height ranges from $115 \mathrm{~cm}$ to $120 \mathrm{~cm}$; the number of its flowers is 5-6. The 'Siberia' variety is a white/near white-colored variety, with its flowering time being 110-120 d, its flower stem length being 90-120 cm, and the number of its flowers being $4-8^{[10,11]}$. Bulbs were provided as frozen $\left(-2^{\circ} \mathrm{C}\right)$. Before planting, they had been stored at $2^{\circ} \mathrm{C}$ for $2 \mathrm{~d}$ and then kept at $0^{\circ} \mathrm{C}, 2^{\circ} \mathrm{C}, 5^{\circ} \mathrm{C}$, and $10^{\circ} \mathrm{C}$ for acclimatization purposes, respectively. After the storage stages, the bulbs were left in the room conditions for a day and at the planting stage, they were treated in a fungicidal solution $(50 \%$ Benomil) for $30 \mathrm{~min}$.

\subsection{Medium treatments}

Five types of soilless media - peat+pumice $(1: 1, \mathrm{v} / \mathrm{v})$, burnt rice hull+pumice $(1: 2, \mathrm{v} / \mathrm{v})$, coarse sand $(>1 \mathrm{~mm})+$ peat $(2: 1, \mathrm{v} / \mathrm{v})$, cocopeat, and peat+perlite $(1: 2, \mathrm{v} / \mathrm{v})$ - and soil alone as the control were tested. After the preparation of the mixtures and before planting, the media were wetted until saturated. No fertilizer was added to the media. The physical and chemical analyses of soil and different soilless media were performed. The organic matter was determined using the Walkley-Black method, as suggested by Black $^{[12]}$. The results of the analyses are given in Tables 1 and 2 .

\subsection{Planting and cultural methods}

Four bulbs were planted in perforated plastic cases $(37 \mathrm{~cm}$ long, $37 \mathrm{~cm}$ wide and $22.5 \mathrm{~cm}$ deep) into $5 \mathrm{~cm}$ depth, at $30 \mathrm{~cm} \times 30 \mathrm{~cm}$ intervals, and in 2 rows on 23 December 2011. Five crates represented one replication (growing media) and a total of twenty bulbs were planted in each replication. Each treatment was designed with three replications. Water and nutrients were applied to the plants with the drip irrigation method. The plants were irrigated using 21/h flowable capillary pipes and 2 rows of drip tape were placed in each crate. The frequency and duration of irrigation were adjusted on the basis of a drainage rate of $30 \%-35 \%$. The plants were irrigated with $100 \mathrm{~cm}^{3}$ of water per plant in each irrigation application. The frequency of irrigation was adjusted once a day in September-October-November and once a week in December-January-April depending on the climatic conditions in the greenhouse. When the plants reached the three-leaf period, fertigation was started. The composition of the nutrient solution was prepared as follows by considering the physical and chemical properties of the growing medium and according to Grasotti et al. ${ }^{[13]}$ and Magnani et al. ${ }^{[14]}$ The nutrient solution consisted of $130 \mathrm{~N}, 62 \mathrm{P}, 185 \mathrm{~K}, 100 \mathrm{Ca}, 93 \mathrm{Mg}$, and $4 \mathrm{Fe}$, whereas $\mathrm{pH}$ values and electrical conductivity values were 5.5-6.0 and 1.2-1.4 mS/cm, respectively.

Table 1 Some physical and chemical properties of the soilless media

\begin{tabular}{lccccc}
\hline \multicolumn{1}{c}{ Properties } & Peat & Cocopeat & Rice Hull & Pumice & Sand \\
\hline $\mathrm{pH}^{*}(1: 5)$ & 6.6 & 7.2 & 6.5 & 8.6 & 8.7 \\
$\mathrm{EC} / \mu \mathrm{S} \cdot \mathrm{cm}^{-1}$ & 159 & 193 & 890 & 44 & 68 \\
Humidity/\% & 68.0 & 81.7 & 9.3 & - & - \\
Dry matter/\% & 32.0 & 18.3 & 90.7 & - & - \\
Organic matter/\% & 91.9 & 89.9 & 81.0 & - & - \\
Ash/\% & 8.1 & 10.1 & 19.0 & - & - \\
Total N/\% & 1.23 & 0.15 & 0.54 & - & - \\
$\mathrm{C} / \%$ & 53.3 & 52.1 & 47.0 & - & - \\
$\mathrm{C} / \mathrm{N}$ & 43.3 & 358.5 & 87.5 & - & - \\
\hline
\end{tabular}

Note:* measured on watery extract 1:5 (v/v).

Table 2 Physical and chemical properties of soil

\begin{tabular}{lc}
\hline \multicolumn{1}{c}{ Properties } & Value \\
\hline $\mathrm{pH} *$ & 8.3 \\
$\mathrm{Lime} / \%,-\mathrm{w} / \mathrm{w}$ & 25.7 \\
$\mathrm{EC} / \mu \mathrm{S} \cdot \mathrm{cm}^{-1}$ & 183 \\
$\mathrm{Sand} / \%$ & 13 \\
$\mathrm{Clay} / \%$ & 31 \\
$\mathrm{Silt} / \%$ & 56 \\
Organic matter$/ \%$ & 1.6 \\
$\mathrm{P} / \mathrm{mg} \cdot \mathrm{L}^{-1}$ & 17 \\
$\mathrm{~K} / \mathrm{mg} \cdot \mathrm{L}^{-1}$ & 259 \\
$\mathrm{Ca} / \mathrm{mg} \cdot \mathrm{L}^{-1}$ & 5502 \\
$\mathrm{Mg} / \mathrm{mg} \cdot \mathrm{L}^{-1}$ & 518 \\
\hline Note $*$ measured on watery extract $1: 2.5(\mathrm{v} / \mathrm{v})$ &
\end{tabular}


The growth periods of the Lilium cultivars grown in 6 different growing media were shown in Figure 2.

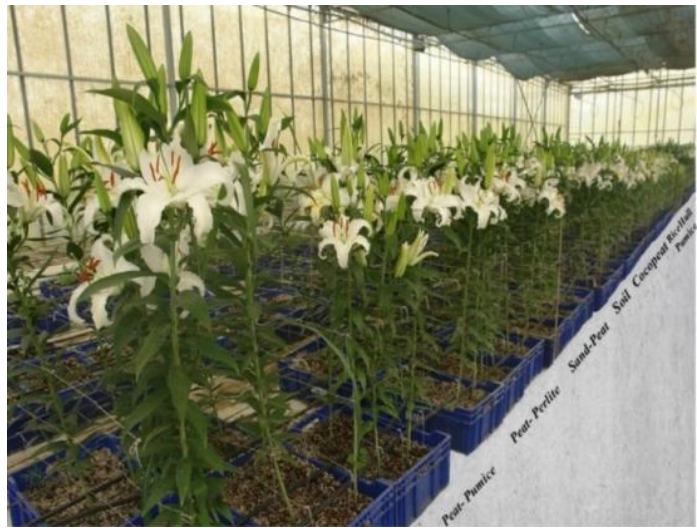

a. Flowering period

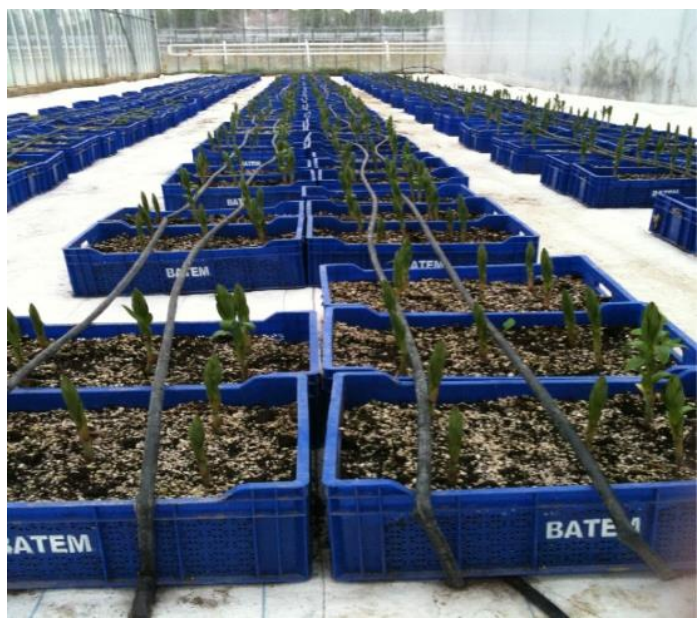

b. Shoot formation period

Figure 2 Growth periods of Lilium cultivars grown in six different growing media

\subsection{Measurements}

In this study, the number of days to flowering, plant height, stem weight, the number of flowers, vase life and the number of leaves were determined according to Addai and Scott ${ }^{[15]}$, Burchi et al. ${ }^{[16]}$, and Prisa et al. ${ }^{[17]}$. The number of days to flowering was the number of days from the time of planting to the blooming of the first bud on each stem (plant). Plant height was measured from the ground level up to the head level of the top flower. Stem weight was the fresh weight of harvested flowers (stem + leaf + flower). The number of florets was recorded by counting them after they had fully opened. Stem diameter was calculated $10 \mathrm{~cm}$ below the first flower. Vase life was considered as the number of days required for the senescence of $50 \%$ of the flowers on each stem (Firstly, water was taken from the harvested flowers. Later on, the lower leaves were cleared and the stems were cut from $50 \mathrm{~cm}$. Finally, they were kept in the climate room with $21^{\circ} \mathrm{C}-22^{\circ} \mathrm{C}$ temperature, $60-70 \%$ relative humidity, and 1000 2500 lux light for $12 \mathrm{~h}$ ). The number of leaves was calculated by counting all the leaves per plant. Thirty sample plants were randomly selected from each treatment and the average was calculated.

\subsection{Experimental design and statistical analysis}

The experiment was set up according to the split-plot experimental design in randomized blocks with 3 replications and a total of 720 bulbs were used, with each replication containing 20 bulbs for each growing medium. The obtained data were subjected to the analysis of variance in Tarist statistical program, and the mean values were compared using Duncan's multiple range tests at the level of $0.05^{[18]}$.

\section{Results and discussion}

Different soilless media had significant effects on growth and flower quality parameters. Data on the vegetative growth and flowering of lily cv. 'Vespucci' and 'Siberia' are provided below.

\subsection{Number of days to flowering}

In the study, the effects of growing media $(p<0.01)$ and years $(p<0.01)$ were significant in terms of the flowering period. The earliest flowering was obtained from the plants grown in the peat+pumice medium (average $154.78 \mathrm{~d}$ ), followed by the plants grown in the sand+peat medium $(156.47 \mathrm{~d})$. The last flowering period was obtained from the plants grown in soil with $163.7 \mathrm{~d}$ on average (Figure 3). Rajera et al. ${ }^{[19]}$ tried the cultivation of 2 varieties of LA hybrid lily bulbs in 7 different growing media. They discovered that M7:M1 (sand+soil+FYM) and vermicompost+cocopeat $(2: 1: 1, \mathrm{v} / \mathrm{v})$ yielded the best result in terms of flowering time, the number of leaves per plant, the number of flowers per plant, stem weight, and vase life. On the other hand, the best result was recorded from sand+soil+FYM $(1: 1: 1, \mathrm{v} / \mathrm{v})$ in terms of plant height, stem length, and the number of flowers.

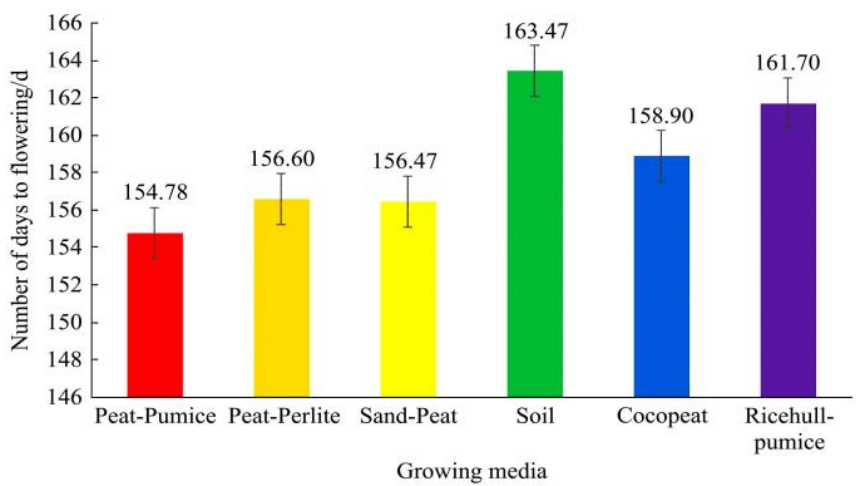

Note: Significance: Variety (V): n.s., Growing media (GM): **, Years (Y): **, V $\times$ GM: n.s., $Y \times G M$ : n.s., $V \times G M \times Y$ : n.s., LSD: 4.21; n.s. presents non-significant at $\mathrm{p}<0.01$; ** presents significant at $\mathrm{p}<0.01$.

Figure 3 Effects of different growing media on the number of days to flowering (days) of lily varieties

The commercial growing period is $110-120 \mathrm{~d}$ in the 'Siberia' variety and $90 \mathrm{~d}$ in the 'Vespucci' variety of lily ${ }^{[10,20]}$. The differences in flowering time are thought to have been caused by different light and temperature conditions and planting dates.

\subsection{Plant height}

The effects of different growing media on the plant height of lily varieties are given in Figure 4. It is shown that the interaction between varieties and growing media creates a significant difference. The longest plant heights of the 'Siberia' and 'Vespucci' varieties were defined as $120.82 \mathrm{~cm}$ and $119.72 \mathrm{~cm}$, respectively. When the growing media were considered independently, it was discovered that the plants grown in the peat+pumice medium had the longest plant height and that the plants grown in soil had the shortest plant height.

Tehranifar et al. ${ }^{[21]}$ stated that the highest flower stem length was obtained in $100 \%$ cocopeat and $40 \%$ peat $+60 \%$ perlite substrates. Likewise, Tribulato and Noto ${ }^{[22]}$ reported that the use of peat and basalt mixture increased the flower stem length in Lilium varieties. Grassotti et al. ${ }^{[13]}$ determined that longer flower stems were found in perlite+coconut, coconut fiber, and the perlite+peat substrate, as compared to clay pellets+coconut fiber and perlite. Lopez et al. ${ }^{[23]}$ reported that the stem length, the spike 
length and the number of florets in the plants grown singly in peat were greater than those of the plants grown singly in perlite in gladiolus (Gladiolus tristis subsp. concolor). Some differences between the results of this study and the findings of the above-mentioned researchers were thought to have been due to the differences in the growing media used as well as their volumes, growth conditions, ecological factors, and the varieties used.

While the flower plant height of the commercial 'Vespucci' variety with a diameter of $16 / 18 \mathrm{~cm}$ was $115-120 \mathrm{~cm}$, the plants we cultivated in the peat+pumice medium had a length of $119.72 \mathrm{~cm}$. In the commercial 'Siberia' variety, the length of the plant was 90-120 cm, while the plants in the peat+pumice medium had a length of $120.82 \mathrm{~cm}$.

\subsection{Number of flowers}

When the number of flowers was considered, although the effects of growing media and varieties were found significant, the interaction between them was found insignificant (Figure 5). The maximum number of flowers was obtained from the plants grown in cocopeat with averages of 7.00 (Siberia) and 5.67 (Vespucci), followed by peat+perlite ( 7.0 flowers) in Siberia and by peat+pumice (13.33 flowers) in Vespucci. The minimum number of flowers (5-5.33 flowers) was obtained from the plants grown in soil. When the varieties were evaluated, the 'Siberia' variety had a larger number of flowers than the 'Vespucci' variety. Sar1 and Celikel $^{[24]}$ reported that the largest number of flowers was obtained from the peat+perlite (6.0 flowers) medium in Oriental Lilium 'Siberia' grown in 6 different growing media (peat + sand, perlite, perlite + peat, soil, peat + sand, and sheep manure + sand).

Chandrakar et al. ${ }^{[25]}$ evaluated the performance of five oriental lily varieties grown in different media (vermicompost, cocopeat, sand, and soil). The maximum number of flowers per plant (3.83) was obtained from the cocopeat medium, while the minimum number of flowers (1.03) was recorded from soil. The difference in the number of flowers per plant may depend on varieties, ecological conditions, and genetic factors.

The number of flowers was reported as 5-6 in the commercial 'Vespucci' variety and, also according to the results we obtained, the number of flowers was 5.67 in the peat+pumice and cocopeat media. On the other hand, the number of flowers was reported as 4-8 in the commercial 'Siberia' variety, while the number of flowers we obtained from the peat + perlite and cocopeat media was 7.

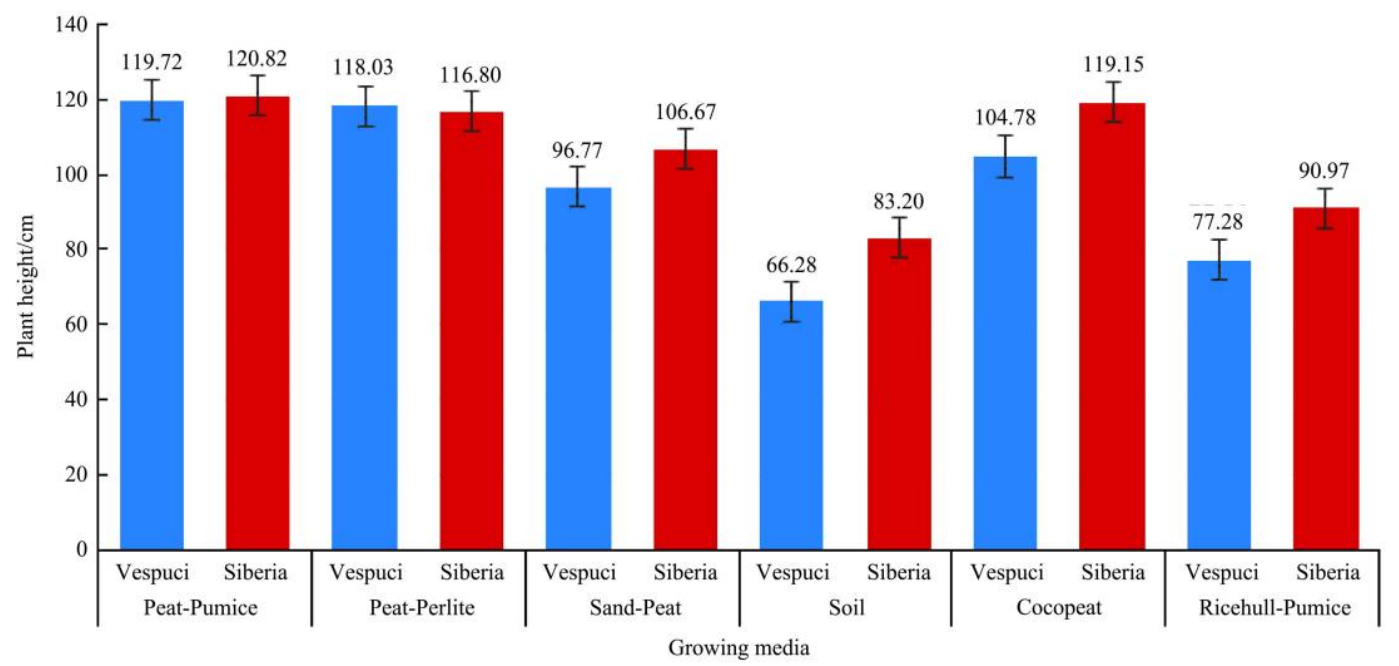

Note: Significance: Variety (V): **, Growing media (GM): **, Years (Y): n.s., V×GM: **, V×GM×Y: n.s., LSD: 6.99; n.s. presents non-significant at $p<0.01 ; * *$ presents significant at $p<0.01$.

Figure 4 Effects of different growing media on the plant height $(\mathrm{cm})$ of lily varieties.

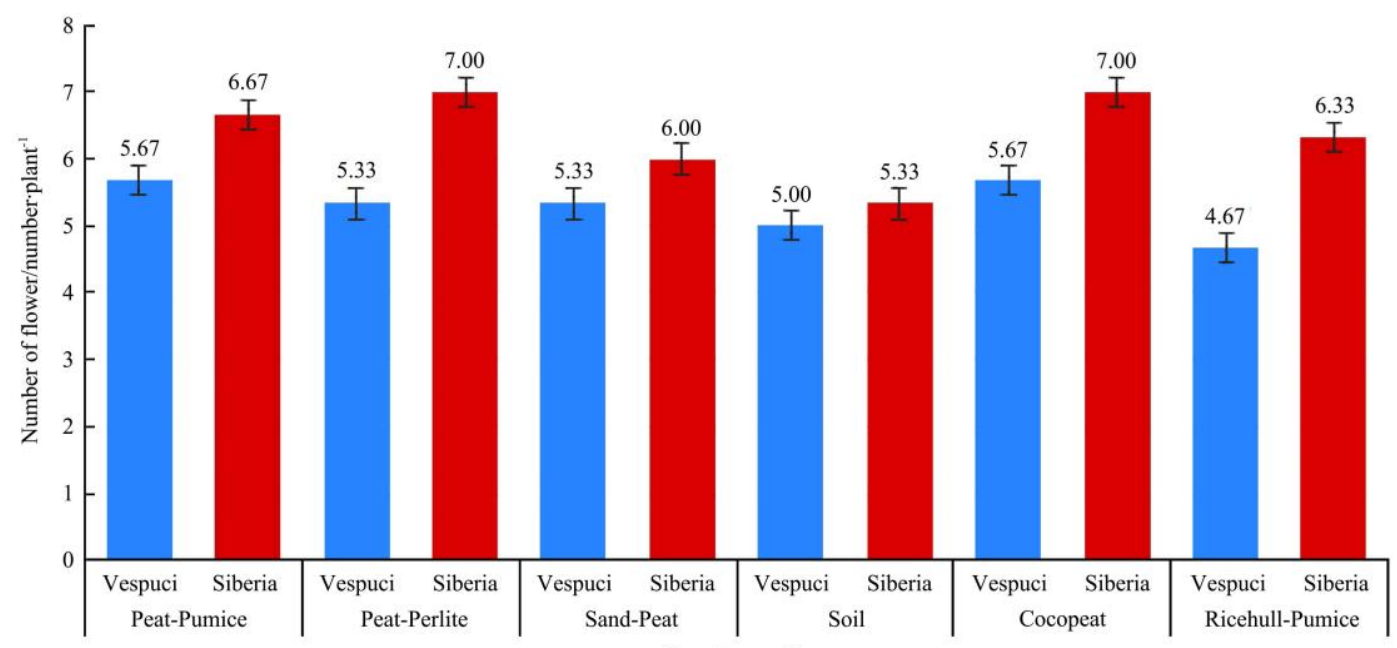

Growing media

Note: Significance: Variety (V): **, Growing media (GM): **, Years (Y): n.s., V×GM: n.s., V×GM×Y: n.s., LSD: 0.43; n.s. presents non-significant at $p<0.01 ; * *$ presents significant at $p<0.01$.

Figure 5 Effects of different growing media on the number of flowers (number/plant) of lily varieties 


\subsection{Vase life}

The effects of varieties, growing media and their interactions on vase life were found quite significant $(p<0.01)$. The longest vase life of the 'Vespucci' variety was obtained from the plants grown in soil with $15.00 \mathrm{~d}$. In the 'Siberia' variety, the plants grown in soil had the longest vase life with $12.50 \mathrm{~d}$ (Figure 6). In this study, the vase life of the flowers grown in soil was found long when compared to the plants from the soilless culture. It was thought that it could have been due to the high calcium content of soil. The results of the analysis are provided in Table 3.

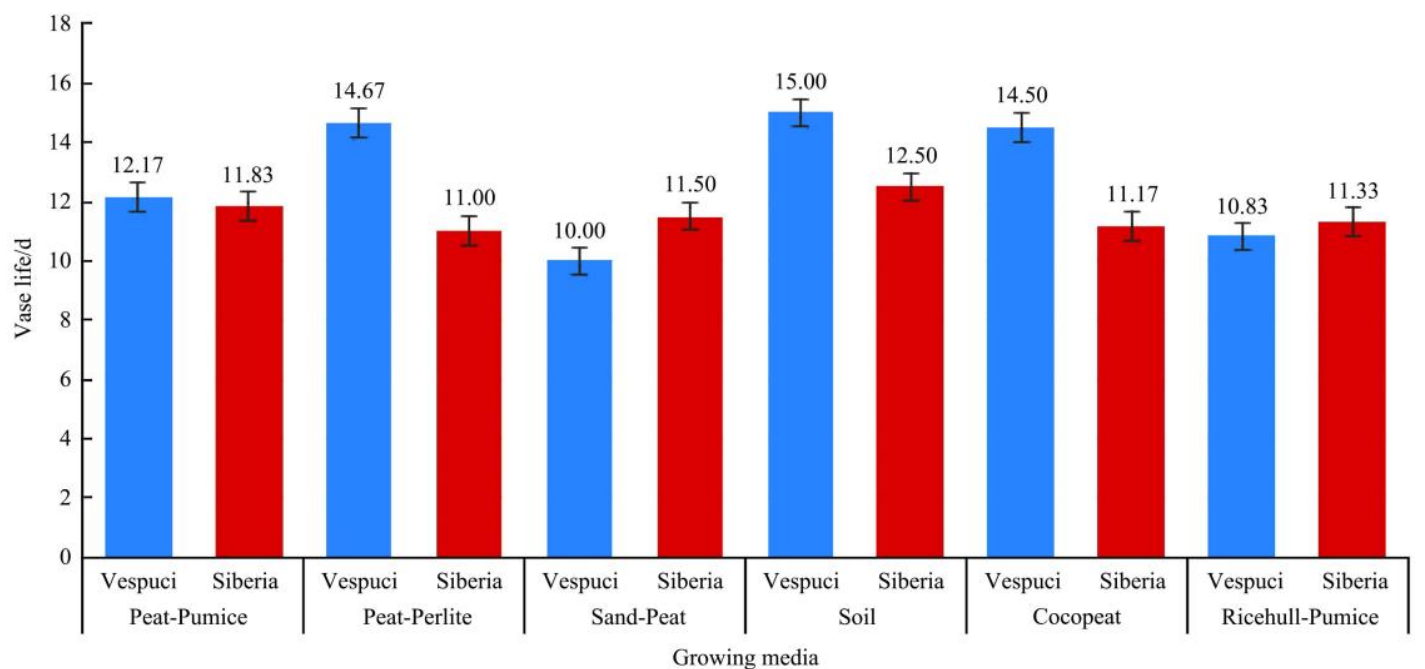

Note: Significance: Variety (V): **, Growing media (GM): **, Years (Y): n.s., V×GM: **, V×GM×Y: n.s., LSD: 1.13; n.s. presents non-significant at $p<0.01 ; * *$ presents significant at $p<0.01$.

Figure 6 Effects of different growing media on the vase life (days) of lily varieties

Table 3 Leaf analysis results of the lily varieties in different growing media

\begin{tabular}{|c|c|c|c|c|c|c|c|c|c|c|}
\hline Varieties/Growing media & $\mathrm{N} / \%$ & $\mathrm{Ca} / \%$ & $\mathrm{~K} / \%$ & $\mathrm{Mg} / \%$ & $\mathrm{P} / \%$ & $\mathrm{Zn} / \mathrm{mg} \cdot \mathrm{L}^{-1}$ & $\mathrm{Cu} / \mathrm{mg} \cdot \mathrm{L}^{-1}$ & $\mathrm{~B} / \mathrm{mg} \cdot \mathrm{L}^{-1}$ & $\mathrm{Mn} / \mathrm{mg} \cdot \mathrm{L}^{-1}$ & $\mathrm{Fe} / \mathrm{mg} \cdot \mathrm{L}^{-1}$ \\
\hline Siberia/Peat +pumice & 2.57 & 1.99 & 4.04 & 0.28 & 0.25 & 316.20 & 21.10 & 43.80 & 170.60 & 671.80 \\
\hline Siberia/Peat+perlite & 2.65 & 1.88 & 3.85 & 0.25 & 0.25 & 383.40 & 24.50 & 45.30 & 189.80 & 750.10 \\
\hline Siberia/Sand+peat & 2.10 & 2.24 & 3.13 & 0.31 & 0.18 & 302.60 & 22.00 & 42.00 & 150.50 & 591.70 \\
\hline Siberia/Soil & 2.12 & 2.52 & 2.54 & 0.32 & 0.17 & 444.20 & 29.80 & 43.30 & 226.80 & 904.30 \\
\hline Siberia/Cocopeat & 2.36 & 0.98 & 4.41 & 0.31 & 0.23 & 349.20 & 25.80 & 51.00 & 160.40 & 593.40 \\
\hline Vespuci/Peat +pumice & 2.58 & 3.43 & 2.48 & 0.54 & 0.28 & 436.40 & 21.50 & 46.50 & 209.50 & 622.20 \\
\hline Vespuci/Peat+perlite & 2.42 & 2.99 & 2.60 & 0.59 & 0.26 & 375.50 & 19.50 & 56.50 & 197.40 & 534.80 \\
\hline Vespuci/Sand+peat & 2.60 & 3.11 & 2.90 & 0.51 & 0.22 & 407.30 & 25.70 & 39.20 & 196.00 & 573.00 \\
\hline Vespuci/Soil & 2.31 & 4.02 & 1.85 & 0.50 & 0.17 & 464.30 & 27.40 & 59.50 & 217.20 & 769.90 \\
\hline Vespuci/Cocopeat & 2.92 & 1.98 & 4.24 & 0.66 & 0.40 & 391.30 & 24.70 & 46.80 & 170.80 & 566.70 \\
\hline Vespuci/Ricehull+pumice & 2.76 & 3.03 & 2.80 & 0.68 & 0.29 & 132.90 & 22.50 & 54.40 & 247.80 & 558.20 \\
\hline
\end{tabular}

One of the three main factors in the senescence of cut flowers is the water balance. Calcium interacts with polygalacturonic acid (PGA) groups and causes water flow. The use of calcium in vase solutions increases water flow through the stems by association with pectin in the xylem cell walls ${ }^{[26]}$. As can be seen in Table 3, the calcium contents of the varieties grown in soil were found higher than those in the soilless media. The vase life results of this study are in agreement with the statements of the other researchers.

\subsection{Stem diameter}

In the evaluation of the data about the stem diameter, it was observed that the varieties and the growing media had statistically significant effects together (Figure 7). The flowers with the thickest stem were obtained from the peat+pumice medium in Siberia with $9.85 \mathrm{~mm}$ and from the cocopeat medium in the 'Vespucci' cultivar with $9.04 \mathrm{~mm}$. The flowers with the lowest stem thickness were obtained from the plants grown in soil with averages of $6.46 \mathrm{~mm}$ and $7.77 \mathrm{~mm}$ (Vespucci and Siberia). Singh et al. ${ }^{[27]}$ found that cocopeat yielded better results in terms of plant height $(108.66 \mathrm{~cm})$ and stem diameter $(8.77 \mathrm{~mm})$ as compared to the other media [garden soil, cocopeat+sand (1:1), and soil+cocopeat (1:1)] in Lilium longiflorum. In addition, Nikrazm et al. ${ }^{[28]}$ reported that the thickest stem diameter was obtained from the cocopeat medium when sand, cocopeat, vermiculite, perlite and the mixtures of two of all these media at an equal volume (50:50) were applied in 'Bernini' (oriental) and 'Cebdazzle' (Asiatic) Lilium varieties.

\subsection{Stem weight}

The effects of the interaction of cultivars and growing media on fresh stem weight were found significant and it was discovered that the plants were grown in cocopeat (averages: $266.13 \mathrm{~g}$ in the 'Vespucci' variety and $353.91 \mathrm{~g}$ in the 'Siberia' variety) showed the most significant effect (Figure 8). Rajera et al. ${ }^{[19]}$ found that the stem weight was recorded best when LA hybrid bulbs were grown in sand+soil+vermicompost+cocopeat. Grassotti et al. ${ }^{[13]}$ recommended cocopeat in terms of stem weight when compared to the other media (perlite and cocopeat, used alone, mixed together or mixed with clay pellets or peat). Nikrazm et al. ${ }^{[28]}$ evaluated the effects of different media on the 'Bernini' (oriental) and 'Cebdazzle' (Asiatic) cultivars and determined the optimum medium. Ten treatments as cocopeat, sand, vermiculite, perlite, 
and the mixtures of each two media at equal volumes (50:50) were conducted. The results demonstrated the superiority of cocopeat over the other media in terms of fresh and dry weights of the stem in both cultivars.

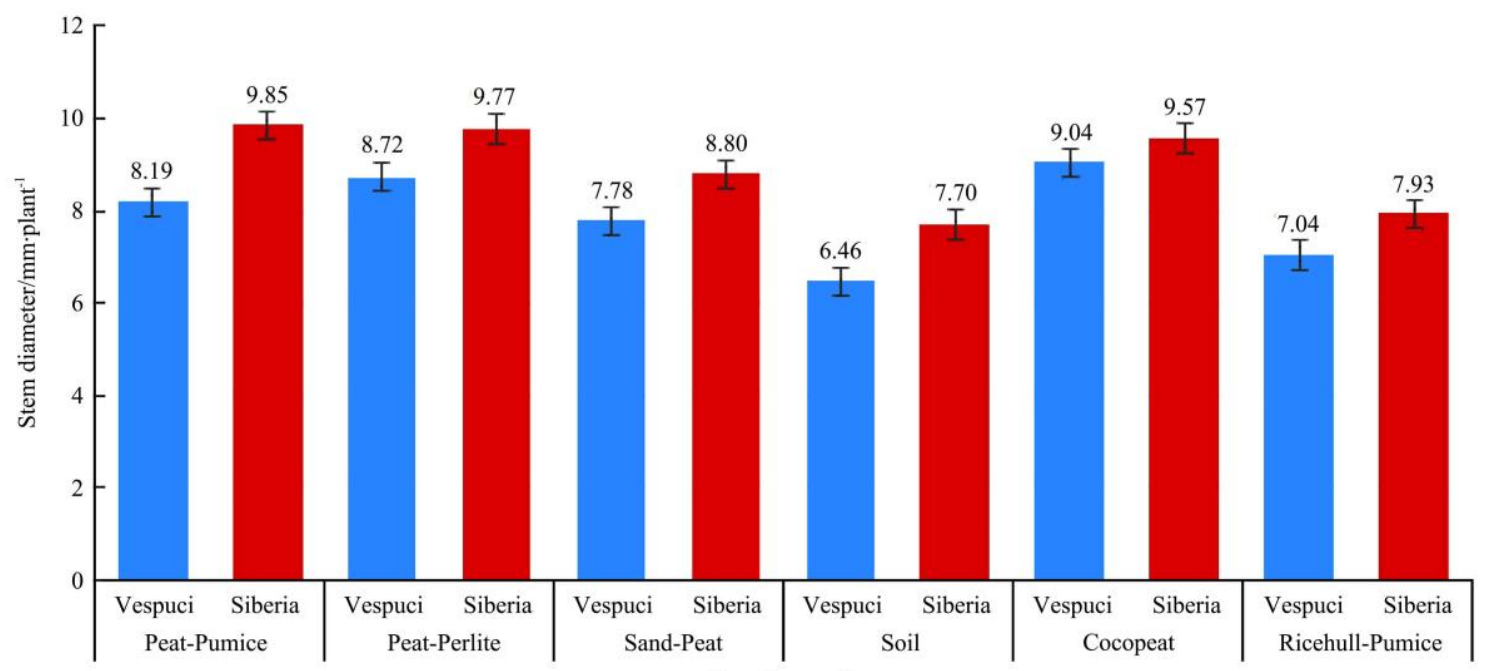

Growing media

Note: Significance: Variety (V): **, Growing media (GM): **, Years (Y): n.s., V×GM: **, V×GM×Y: n.s., LSD: 0.62; n.s. presents non-significant at $p<0.01$; ** presents significant at $p<0.01$.

Figure 7 Effects of different growing media on the stem diameter $(\mathrm{mm})$ of lily varieties

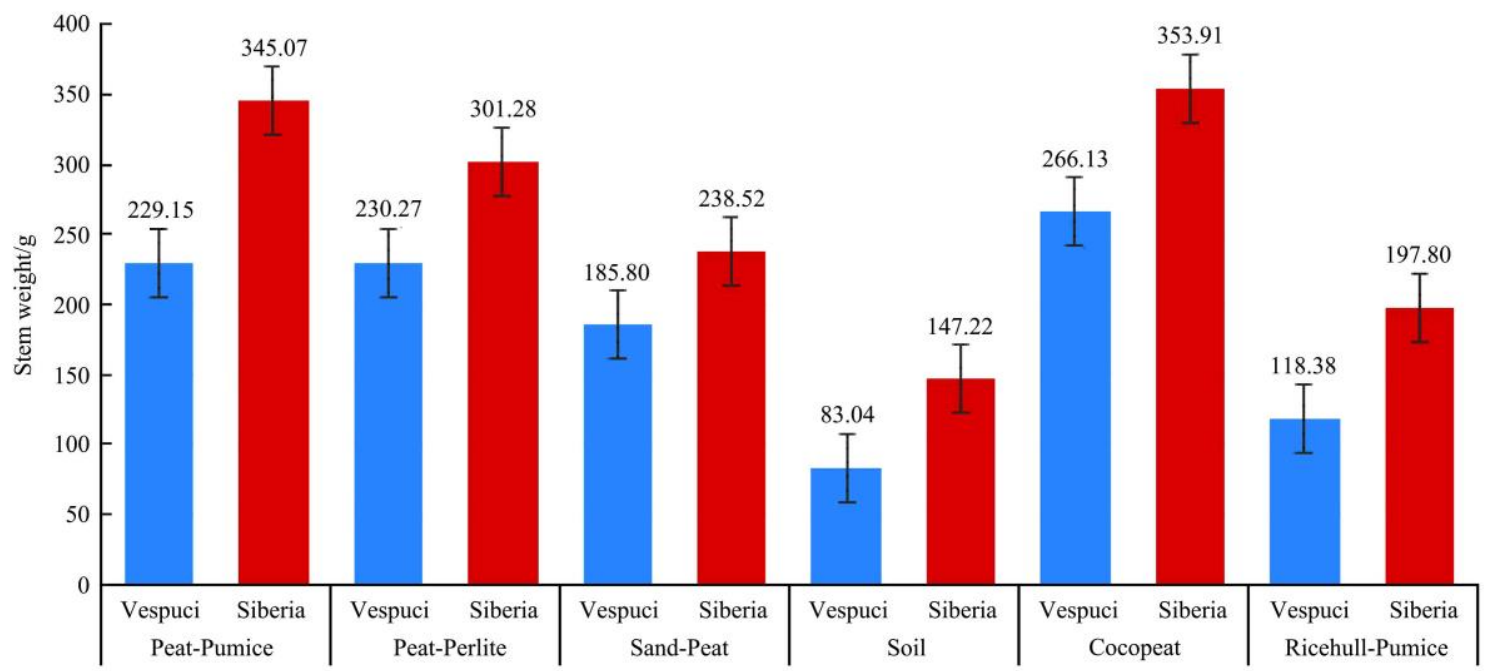

Growing media

Note: Significance: Variety (V): **, Growing media (GM): **, Years (Y): n.s., V×GM: **, V×GM×Y: n.s., LSD: 22.5; n.s. presents non-significant at $p<0.01$; ** presents significant at $p<0.01$.

Figure 8 Effects of different growing media on the stem weight $(\mathrm{g})$ of lily varieties

\subsection{Number of leaves}

In the study, varieties and growing media were statistically significant in terms of the number of leaves. The maximum number of leaves was obtained from the plants grown in rice hull+pumice (mean 57.42). The minimum number of leaves was obtained from the plants grown in the cocopeat medium (52.02) (Figure 9). Similarly, Jong et al. ${ }^{[29]}$ determined that the largest number of leaves was obtained from the rice hull, sawdust, and pine bark medium $(1: 1: 1 ; \mathrm{v} / \mathrm{v})$ in Lilium cv. 'Orange Pixie'. Tehranifar et al. ${ }^{[21]}$ grew the Lilium plants in 3 different growing media - M1 (100\% cocopeat), M2 (50\% gravel+50\% sand), and M3 (40\% peat $+60 \%$ perlite) - and reported that the largest number of leaves was obtained from M2. Grassotti et al. ${ }^{[13]}$ reported that the minimum number of leaves was obtained from peat+perlite. In another study, the largest number of leaves (57.73) in Oriental Lilium 'Siberia' was recorded in the peat+sand medium, whereas the lowest value $(33.1$ pcs $)$ was obtained from sheep manure+sand ${ }^{[24]}$.
According to the findings, it is revealed that peat pumice has the best values in terms of flowering time, plant height, number of flowers and vase life, which are the most important commercial quality parameters (Table 4). Comparison of commercial properties of Vespucci and Siberia Lilium varieties in terms of quality parameters are shown in Table 5.

Differences between the plants grown in the soil and the plants grown in other growing media were observed. The lowest parameters were obtained from the plants grown in soil, except for the vase life. The flowering period of the Vespucci variety grown in the soil was $2 \mathrm{~d}$ longer than the cultivation in different growing media and the flowering time of the Siberian variety was $7 \mathrm{~d}$ longer. It was also observed that the plant height of Vespucci variety grown in soil was $53.44 \mathrm{~cm}$ shorter than the grown in peat-pumice, plant height of Siberia variety grown in soil was $37.62 \mathrm{~cm}$ shorter.

Consequently, it was observed that the peat+pumice and peat+perlite media yielded more successful results than the other media in the cultivation of lily species and varieties. These results 
were found in agreement with the results of Tribulato et al. ${ }^{[30]}$ and Tehranifar et al. ${ }^{[21]}$ Many of the results reported here are in good agreement with those reported by Jong et al. ${ }^{[29]}$, Tribulato et al. ${ }^{[30]}$, Grassotti et al. ${ }^{[13]}$, Tehranifar et al. ${ }^{[21]}$ and Sarı and Çelikel ${ }^{[24]}$.

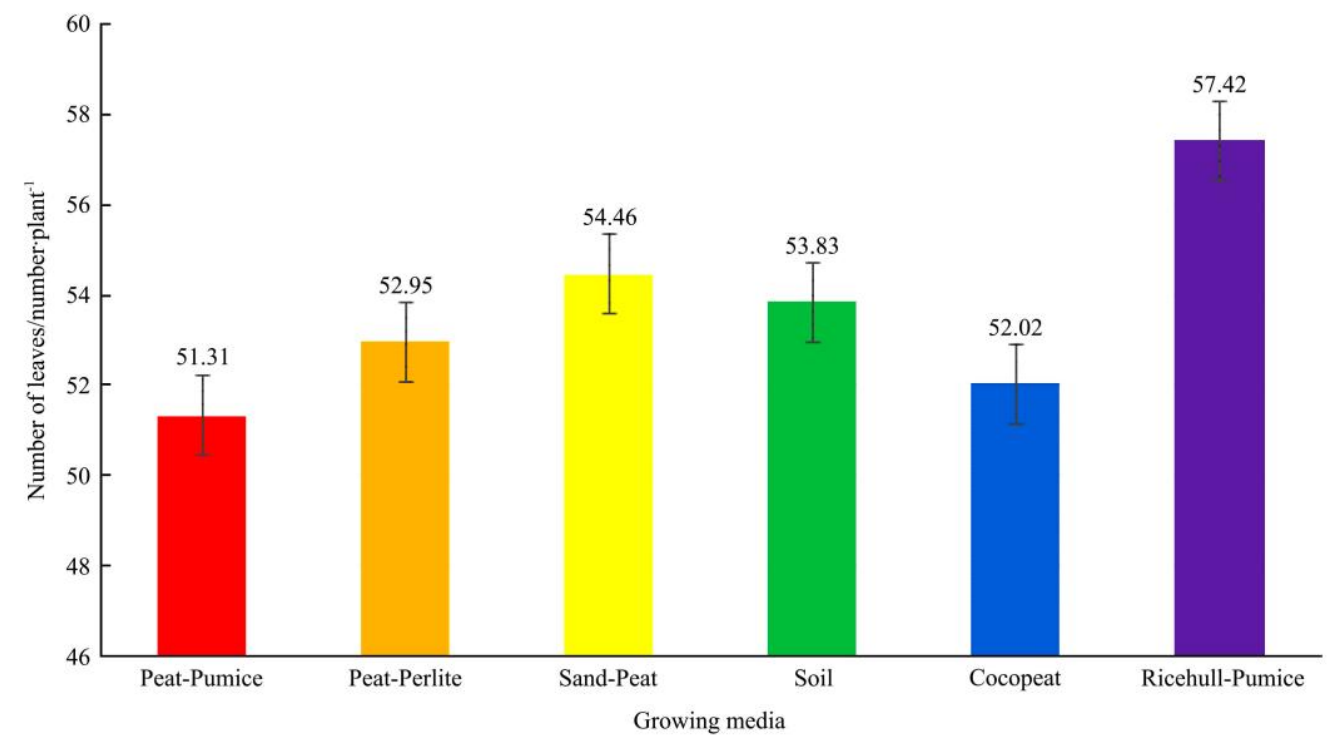

Note: Significance: Variety (V): **, Growing media (GM): **, Years (Y): n.s, V×GM: n.s, Y×GM: *, V×GM×Y: n.s, LSD: 3.98; n.s presents non-significant at $p<0.01$; ** presents significant at $p<0.01$.

Figure 9 Effects of different growing media on the number of leaves (number/plant) of lily varieties

Table 4 Best results of growing media in terms of the most important commercial quality parameters (Shown by $\mathbf{X}$ )

\begin{tabular}{|c|c|c|c|c|c|c|c|c|}
\hline \multirow{2}{*}{ Growing Media } & \multicolumn{2}{|c|}{ Flowering time } & \multicolumn{2}{|c|}{ Plant height } & \multicolumn{2}{|c|}{ Flower number } & \multicolumn{2}{|c|}{ Vase life } \\
\hline & Vespucci & Siberia & Vespucci & Siberia & Vespucci & Siberia & Vespucci & Siberia \\
\hline Peat-pumice & $\mathrm{X}$ & $\mathrm{X}$ & $\mathrm{X}$ & $\mathrm{X}$ & $\mathrm{X}$ & & & \\
\hline Peat-perlite & & & & & & $\mathrm{X}$ & & \\
\hline \multicolumn{9}{|l|}{ Sand-peat } \\
\hline Soil & & & & & & & $\mathrm{X}$ & $\mathrm{X}$ \\
\hline Cocopeat & & & & & $\mathrm{X}$ & $\mathrm{X}$ & & \\
\hline Ricehull-pumice & & & & & & & & \\
\hline
\end{tabular}

Table 5 Comparison of commercial properties of Vespucci and Siberia Lilium varieties in terms of quality parameters

\begin{tabular}{|c|c|c|c|c|}
\hline \multirow{2}{*}{ Parameters } & \multicolumn{2}{|c|}{ Commercial properties } & \multicolumn{2}{|c|}{ Best results } \\
\hline & Vespucci & Siberia & Vespucci & Siberia \\
\hline Plant height $/ \mathrm{cm}$ & $115-120$ & $100-110$ & 119.77 (peat-pumice) & 120.82 (Peat-pumice) \\
\hline Flower number & $5-6$ & $4-6$ & 5.67 (Peat pumice) & 7 (Peat-perlite) \\
\hline Vase life/d & $12-14$ & 14 & 15 (Soil) and 14.67 (Peat-perlit) & 12.5 (soil) and 11.83 (peat-pumice) \\
\hline
\end{tabular}

\section{Conclusions}

In this study, soilless cultivation assured satisfactory results in terms of the growth of plants and cut flower quality. The soilless media were found statistically significant $(p<0.01)$ in most of the criteria examined in this study.

When the flowering time, flower stem length, the number of florets and stem weight - the four most important commercial quality parameters - were considered, the researchers found that the peat+pumice and cocopeat media yielded the best results with the varieties used, followed by the peat+perlite medium. The lowest values except vase life were obtained from the plants grown in soil. The plants were grown in the soilless culture blossomed $9 \mathrm{~d}$ earlier than the plants grown in soil. Based on the results of this study, the peat+pumice medium performed better than the other media and can, therefore, be recommended as the best one.

\section{Acknowledgements}

This work was financially supported by the General Directorate of Agricultural Research and Policies (TAGEM) (Grant No. BBSS-10-04). The author acknowledges Assoc. Prof. Köksal Aydinşakir, Ayşe S. Kaya and Bayram Kolak for contributions to the study.

\section{[References]}

[1] Wu X W, Wang L H, Wu L F, Qu S P, Suh J K, Wang J H. Native species of the genus Lilium and the closely related Nomocharis in Yunnan, China. Floriculture and Ornamental Biotechnology, 2012; 6: 28-38.

[2] Van Tuyl J M, Arens P. Lilium: Breeding history of the modern cultivar assortment. Acta Hortic., 2011; 900: 223-230.

[3] Van Gelder K. Area used for production of lily bulbs in the Netherlands 2008-2019. Statistics portal, $2020 . \quad$ Available: https://www.statista.com/statistics/641926/total-area-used-for-production-o f-lily-bulbs-in-the-netherlands/. Accessed on [2020-06-16].

[4] AIPH/Union Fleurs. International Statistics Flowers and Plants, 
2016; 190p.

[5] Gohil P, Gohil M, Rajatiya J, Halepotara F, Solanki M, Malam V R, et al. Role of growing media for ornamental pot plants. Int. J. Pure App. Biosci. 2018; 6(1): 1219-1224

[6] Fascella G, Zizzo GV. Effect of growing media on yield and quality of soilless cultivated rose. Acta Horticulturae, 2005; 697: 133-138.

[7] Asaduzzaman M, Saifullah M, Salim Reza A K M, Mollick Hossain M, Halim G M A, Asao T. Influence of soilless culture substrate on improvement of yield and produce quality of horticultural crops. In: Asaduzzaman M (Ed.), Soilless culture-Use of substrates for the production of quality horticultural crops. Intech, 2015; pp.1-32.

[8] Ryota T, Kazunori M, Musao T, Kazuyoshi S. Studies on the hydroponics of oriental hybrid lily. Journal of the Niigata Agricultural Research Institute, 2002; 5: 65-74.

[9] Lim Ki B, Van Tuyl J M. Lily: Lilium hybrids. Title Lily Subtitle Lilium hybrids, 2006; (19): 513-532.

[10] Gill S, Dutky E, Schuster C, Wadkins S, Klick S. Production of hybrid lilies as cut flowers. 2006; 16p.

[11] Anonymous. Oriental Lily 'Siberia'. Available: https://davesgarden.com/ guides/pf/go/93057/\#b. Accessed on [2020-02-13].

[12] Black C A. Methods of soil analysis. Part 2. Amer. Society of Agronomy Inc., Madison, 1965; pp.1372-1376.

[13] Grassotti A, Nesi B, Maletta M, Magnani G. Effects of growing media and planting time on lily hybrids in soilless culture. Acta Hort. (ISHS), 2003; 609: 395-399.

[14] Magnani G, Grassotti A, Nesi B. Lapillus growing medium for cut bulbous flowers in soilless culture. Acta Hort. (ISHS), 2003; 609: 389-393.

[15] Addai I K, Scott P. Influence of bulb sizes at planting on growth and development of the common hyacinth and the lily. Agric. Biol. J. N. Am., 2011; 2(2): 298-314.

[16] Burchi G D, Prisa A, Ballarin A, Grassotti A. Effect of leaf treatments on flower quality and shelf life in Asiatic lily. Acta Hort, 2009; 906: 19-24.

[17] Prisa D, Burchi G, Antonetti M, Teani A. Use of organic or inorganic substrates for reducing the use of peat and improving the quality of bulbs and inflorescences in Asiatic Lily. In: Proc IInd on the Genus Lilium., 2011; pp.143-148

[18] Gomez K A, Gomez A A. Statistical procedures for agricultural research. In: An Int. Rice Res. Inst. Book. New York: John Wiley \& Sons Inc., 1984; 680 p.
[19] Rajera S, Sharma P, Sharma B K P. Effect of different growing media on growth and flower production of LA Hybrid Lily. Int. J. Curr. Microbiol. App. Sci., 2017; 6(8): 2076-2089.

[20] Anonymous 2019 c. Siberia. Available: https://www.vws-flowerbulbs.nl/flower-bulb/ 689/siberia. Accessed on [2019-01-17].

[21] Tehranifar A, Selahvarzi Y, Alizadeh B. Effect of different growing media on growth and development of two Lilium (Oriental and Asiatic Hybrids) types in soilless conditions. Acta Horticulturae, 2011; 900: 139-142.

[22] Tribulato A, Noto G. Forcing oriental and Asiatic lilies in soilless culture Acta Hort., 2001; 559: 639-654.

[23] Lopez J, González A, Cos J E, Guerrero, L, Fernández, J A. Influence of different types of substratum on growth and flowering of gladiolus tristis subsp. concolor. Acta Horticulturae, 2008; 779: 513-520.

[24] Sarı Ö, Çelikel F. Effects of different growing medium on flower quality and bulb yield of Oriental Lilium 'Siberia'. International Journal of Agriculture and Wildlife Science, 2017; 3(2): 54-60.

[25] Chandrakar U, Fatmi U, Bharti S, Swastika S. Effect of growing medias on different varieties of oriental Lilium (Lilium orientalis) under Shadenet in Allahabad Agro climatic conditions. Int. J. Curr. Microbiol. App. Sci., 2018; 7(12): 2114-2121.

[26] Huerta Cortes M, Arriaga Frias M, Gonzalez Moreno S, Mandujano Pina M, Cruz Guzman M, De la G H, et al. The effects of calcium on postharvest water status and vase life of Rosa hybrida cv. Grand Gala. International Journal of Agriculture \& Biology, 2011; 13(2): 297-300.

[27] Singh B N, Ranjan S, Sunil K. Effect of substrates on Lilium (Lilium longiflorum L.) programming in container system. Indian Journal of Horticulture, 2016; 73(3): 456-459.

[28] Nikrazm R, Ajirlou S A, Tabatabaei S J. Effect of different mediaon vegetative growth of two Lilium cultivars in soilless culture. Journal of Science and Technology of Greenhouse Culture-Isfahan University of Technology, 2011; 2(6): 1-9.

[29] Choi J J, Lee J S, Choi J M. Effect of physicochemical properties of growing media on growth, nutrient uptake and soil nutrient concentration in pot plant production of Asiatic hybrid lily 'Orange Pixie'. J. Korean Society for Horticultural Sci., 2002; 43(6): 747-753.

[30] Tribulato A, Noto G, Argento S. Soilless culture on quality production in lily. Acta Horticulturae, 2003; 614: 749-754. 